\title{
Smarter Choices: Assessing the potential to achieve traffic reduction using 'soft measures'
}

\author{
Cairns S, Sloman L, Newson C, Anable J, Kirkbride A and Goodwin P \\ Contact author's details: Dr S Cairns, Transport Studies, UCL, Gower Street, \\ London, WC1E 6BT. Email: sally@transport.ucl.ac.uk. Telephone: 07785182141
}

\begin{abstract}
:
In recent years, there has been growing interest in a range of transport policy initiatives which are designed to influence people's travel behaviour away from single-occupancy car use and towards more benign and efficient options, through a combination of marketing, information, incentives and tailored new services. In transport policy discussions, these are now widely described as 'soft' factor interventions or 'smarter choice' measures or 'mobility management' tools. In 2004, the UK Department for Transport commissioned a major study to examine whether large scale programmes of these measures could potentially deliver substantial cuts in car use. The purpose of this paper is to clarify the approach taken in the study, the types of evidence reviewed and the overall conclusions reached. In summary, the results suggested that, within approximately 10 years, smarter choice measures have the potential to reduce national traffic levels by about $11 \%$, with reductions of up to $21 \%$ in peak period urban traffic. Moreover, they represent relatively good value for money, with schemes potentially generating benefit: cost ratios which are in excess of 10:1. The central conclusion of the study was that such measures could play a very significant role in addressing traffic, given the right support and policy context.
\end{abstract}

\section{Acknowledgements:}

The support of the Rees Jeffreys Road Fund, which has enabled the preparation of this paper, is very gratefully acknowledged. In addition, the authors wish to gratefully thank the client team at the Department for Transport, all the different experts and practitioners working in this area who contributed to the study and the reviewers of this paper for their helpful comments. 


\section{Introduction}

Growing levels of traffic, together with their associated congestion and pollution, are a cause for concern throughout the world. It is no longer thought possible to 'build our way out of trouble' through road construction, and this has led to increasing interest in a range of alternative ways to manage traffic levels. In particular, in recent years, there has been growing interest in a range of transport policy initiatives which combine marketing, information, incentives and, in some cases, tailored new services, in order to influence people's travel behaviour away from single-occupancy car use and towards more benign or efficient ways of travelling. In transport policy discussions, these are now widely described as 'soft' factor interventions or 'smarter choice' measures or 'mobility management' tools.

In 2004, the UK Department for Transport commissioned a team of 6 specialists, coordinated by the ESRC Transport Studies Unit at University College London and the independent consultancy Transport for Quality of Life, to undertake a major study into the potential of 'soft' or 'smarter choice' measures to reduce traffic levels in the UK in the next 10 years ${ }^{1}$. The central question that the study aimed to address was - could large scale programmes of smart measures potentially deliver substantial cuts in car use, or is their impact only likely to be marginal?

This is a particularly dynamic field of transport policy, in which many new schemes and initiatives are being developed on an ongoing basis. To the authors' knowledge, the work reported here remains the most systematic and comprehensive overview of the potential of these types of measures. The main report of the study (Cairns et al, 2004) runs to nearly 400 pages, with a supporting 300 page case study volume (Anable et al, 2004), and it is not possible to reproduce the detail from the study about individual measures in this paper. Instead, the purpose of this paper is to clarify the approach taken in the study, the types of evidence reviewed and the overall conclusions reached.

Specifically, this paper begins by describing the type of measures studied and the study methodology, followed by a brief summary of previous literature. The next part of the paper takes one of the soft measures studied - workplace travel plans - to illustrate the type of evidence and analysis used to draw conclusions about how significant such activities could be, and how much they typically cost. The findings about all the measures studied, as derived from equivalent analysis, are then briefly reported. Next, the paper provides more detail about the overall cost impact ratios calculated, and the process used for calculating the overall impacts on traffic that a package of such measures could achieve. Finally, some broader contextual issues are considered.

\section{Overview of the study approach}

The terms 'soft' or 'smarter choice' measure are used to cover a range of initiatives. The word 'soft' was originally used to distinguish them from 'hard' measures such as physical improvements to transport infrastructure or operations, traffic engineering, control of road space and changes in price, although some soft factors do include elements of this nature. (For example, workplace travel plans often including parking

\footnotetext{
${ }^{1}$ The term 'soft' has been used in the literature for several years, albeit with some misgivings. The term 'smarter choices' was coined at the final stage of this study by the Department for Transport clients, as an alternative label for the type of measures studied.
} 
restrictions). 'Soft' also refers to the nature of the traveller response, with initiatives often addressing psychological motivations for travel choice as well as economic ones. There is an emphasis on management and marketing activities rather than operations and investment. The measures are often largely or entirely omitted from established modelling and appraisal techniques, which deal with measures that are assumed to be more reliably understood (although the incorporation of such measures into standard modelling tools is undoubtedly an important issue).

In the study reported here, 10 types of measures were included, namely:

- workplace travel plans - where employers put in place a package of measures primarily aimed at encouraging and enabling their employees to travel to work more sustainably.

- school travel plans - where a package of measures is introduced at an individual school to encourage and enable children to travel to school more sustainably.

- personalised travel planning - where individuals are offered information carefully tailored to their personal and locational circumstances to encourage and enable them to travel more sustainably.

- $\quad$ public transport information and marketing - which includes advertising campaigns, the provision of information in more accessible formats and simplified ticketing schemes.

- travel awareness campaigns - which involve a wide range of media aimed at improving general public awareness of the problems resulting from transport choices, and what can be done to solve problems, including changing personal behaviour.

- car clubs - an alternative to private car ownership, where individuals are encouraged to join a club that gives them access to a number of vehicles parked in their neighbourhood, where they pay when they use vehicles.

- car sharing schemes - where individuals are encouraged to share their private vehicles for particular journeys (also known as 'car pooling' or 'ride sharing' in other countries).

- teleworking - where employers encourage employees to adopt a range of remote working practices, including working at home or in a closer location than their main workplace, for some or all of the time.

- teleconferencing - where telecommunications are used to facilitate contacts that might otherwise have involved business travel.

- home shopping - where customers purchase goods which are subsequently delivered directly to them, rather than purchasing and transporting them from a store.

To examine the potential of these different measures, the study methodology involved a number of stages. These included:

\section{a) A review of previous overview studies of soft measures}

Seven overview studies were identified and analysed, as discussed in the next section.

\section{b) A review of the literature about each of the 10 measures listed above}

Over 250 references about individual measures were reviewed in detail, with many of these references having themselves collated together results from different initiatives.

\section{c) The creation of a long-list of approximately 60 case studies of smarter choice schemes that had been implemented in the UK}


This was drawn up based on the project team's knowledge, strengthened by consultation with experts and the UK Department for Transport. Telephone conversations, web searches and analyses of local authority progress reports were then used to obtain further information about each suggested case study. This information was summarised, and some of this material was used in the main report.

\section{d) Detailed interviews with 24 case studies}

From the long-list of 60 case studies, 24 case studies were selected. In making these choices, key priorities were that the selection should aim for a balance between metropolitan, urban and rural areas; that more than one measure should be investigated in at least some of the case study areas to seek insight into synergy between measures; and that the selection should include some examples of local authorities that had been less successful in a particular field. (This was taken to mean that they had tried to implement a particular measure but not made great progress, rather than that they had not shown any interest in the measure at all). A further selection criterion was that the organisation involved should have carried out formal monitoring or have other relevant data available about the impacts of the initiative on car use. Having chosen the case studies, a discussion guide was developed for each of the 10 measures, and interviews took place between July and September 2003. Initial interviews were usually with one to three people, with followup work involving contact with further staff and a number of rounds of consultation and redrafting with all those involved - up to 30 further e-mail and telephone contacts per interview.

\section{e) Analysis of the information gathered}

Following the collation of the evidence, each measure was analysed individually, using a series of specific topic headings to guide the analysis. The general topics examined for each smarter choice measure were:

- Where have different interventions been used - what is the scope of current experience?;

- What is the scale of existing interventions - how many people have been affected, and are there particular types of people or types of areas where these initiatives are particularly appropriate?;

- What is known about the effects of each initiative on car use?;

- How do impacts alter over time?;

- What other effects have been achieved, such as improved accessibility?;

- What resources have been needed to achieve these effects, in terms of both staffing and budgets?;

- Is there any information about synergy between particular interventions and other soft or hard measures?;

- In areas where smarter choice measures have been implemented, what does data available from other sources indicate about overall trends in car traffic levels?;

- In the future, what is the likely viable scale, cost and impact of such interventions, if they are scaled up, and what are the key issues and policies involved in scaling up such measures?

The final part of the study then drew together the overall conclusions about the potential traffic impacts of each measure, and its cost effectiveness, together with more general observations about synergy, the importance of context, the offsetting effects of induced traffic and changes in effects over time. 
It should be noted that the conventions for reporting the impacts of different measures were often different, and used different units - varying from overall estimations of impacts on traffic, through to estimations of impacts on car kilometres or car trips. In both the main study and this paper, great care has therefore been taken to make sure that the correct units are quoted in relation to any reported data. When looking at individual measures, the conventions typically used for analysing that measure were used. For example, for workplace travel plans, the reduction in the share of trips made as a car driver was used as the main measure of impact. Various techniques were then used to 'standardise' the impacts of the different measures for the overall calculations (as described in this paper in the sections on 'cost impact ratios' and 'overall impacts on traffic').

\section{f) Consultation and revision}

Following completion of the study, a substantial consultation phase with external experts was undertaken in the early part of 2004. Chapters about the individual smarter choice measures were sent to the case study interviewees and other experts in each field. Approximately 110 people were consulted in total. Overview chapters were subject to intensive scrutiny by different parts of the UK Department for Transport. The material was then significantly revised, and finalised in the light of comments received.

\section{Review of previous studies}

In addition to an extensive literature reporting evidence on specific measures, seven previous studies were identified which had, themselves, reviewed national and international evidence in order to make estimates of the overall effect of a package of soft measures on traffic levels in British conditions. These had been undertaken by Dodgson et al (1997, 2000), WS Atkins (1999), Halcrow Group (2001, 2002), James (2002), Sloman (2003), Steer Davies Gleave (2003) and Transport for London (2003).

Of these, the Halcrow work had been particularly influential, though controversial when compared with other study findings, in that it assumed that soft measures only had limited potential for traffic reduction, although allowing, in principle, for bigger effects in specific locations of interest. Their order of magnitude informed Departmental advice to the UK Multi-Modal Studies teams, who were guided towards the total potential effect of a package of smarter choice measures being around $5 \%$. Subsequent commentators, including James (2002) and three peer reviewers (Goodwin 2003, Bonsall 2003 and Headicar 2003) all concluded that this work underestimated the potential of smarter choice measures.

As part of our study, the seven studies identified above were all reanalysed, including contact and discussions with the original authors. This analysis suggested that the main causes of differences between studies were:

- Issues of measurement and definition;

- Differences in the assessment of the realistic pace of future policy initiatives and market developments;

- Differences between 'expected' and 'potential' outcomes; and

- Differences in the range of measures included in the studies.

In discussions, Halcrow clarified that their study made the policy presumption that, broadly speaking, there would be no great increase in priority or Government attention given to this area of work, (Bayliss, 2004). In contrast, some of the other studies had focused instead on the potential of such measures if Government policy 
attempted to maximise their impacts. Hence, a significant cause of discrepancy in findings was due to different assumptions about the future intensity of the implementation of such measures.

A summary of the results is given in table 1 .

$<$ Insert table 1 about here>

Overall, the lowest estimates of effect given in the studies tended to emerge when it was assumed that there would be little momentum for such policies; when the impacts of specific factors were averaged over 24 hour, national traffic flows; and/or when caveats were made about induced traffic (i.e. the danger that any reductions in car traffic generated through soft measures would be offset by other people choosing to drive more). At the other extreme, the highest figures from the studies emerged as a result of assuming the simultaneous application of many different, consistent initiatives (including supporting 'hard' measures), and where results were expressed as a proportion of the traffic levels in a specific locality, by journey purpose or by time of day.

Given the sharpness of the debate engendered by the reports, our study found a surprisingly consistent underlying picture emerging when the data were reanalysed. In particular, the results suggested that, with lower intensity application and/or without support from complementary hard measures, there was scope for soft measures to reduce traffic levels, but not very much: perhaps $4 \%$ or $5 \%$ at the national level, with a range around this according to local circumstances. With higher intensity application (and emphasising the importance of supportive hard measures either by assumption or explicitly), the estimated potential for soft factor interventions was to reduce traffic levels by $10 \%$ to $15 \%$ as a national average, and $15 \%$ to $20 \%$ in favourable local conditions. There were also some estimates that, in specific circumstances, figures higher than this could be achieved, again, assuming that appropriate supportive hard measures were in place.

Two measures, workplace and school travel plans, were common to six of the seven studies, the estimated effect ranging from the lowest figure of about $1 \%$ of traffic, to the highest in the best specific local circumstances of $9 \%$. The central estimates for workplace and school travel plans, taking the studies together, were $3 \%$ of traffic nationally and $8 \%$ in the best local conditions.

These figures provided a useful basis against which to compare our own estimates.

\section{Analysis of individual measures - the example of workplace travel plans}

The main part of our report involved analysing each of the 10 individual measures in turn, attempting to address the key study topics outlined earlier. The information base for each was substantial, and it is not possible to summarise all of the conclusions here. To give an indication of the type of analysis conducted, some of the findings and conclusions relating to workplace travel plans are reported in this section. Following sections then report on the findings for the other measures, which were based on the same type of analysis.

\section{a) Evidence assessed}

In analysing workplace travel plans, the main sources of evidence used were: 
- Detailed case study evidence from seven workplace travel plan programmes, taking place in Birmingham, Bristol, Buckinghamshire, Cambridgeshire, Merseyside, Nottingham and York.

- Information from related case studies, namely the car sharing schemes in Milton Keynes and Buckinghamshire, the use of personalised journey plans as part of South Yorkshire PTE's Travel Options Planning Service, teleworking and teleconferencing at British Telecom and elements of travel awareness campaigning in York.

- Work by University of Westminster (1998), Steer Davies Gleave (2001), Addison and Fraser (2002), Rye (2002) and internal Department for Transport analysis about the scale of workplace travel plan activities, (although only Rye, 2002, gave estimates for the scale of impacts across all employers, rather than for specific categories of employers).

- Studies by Organisational Coaching/Shreffler (1996), Shoup (1997), Ligtermoet (1998), TCRP (1994), Touwen (1999), Napier University, Open University and WS Atkins (2001) and Cairns et al (2002) about the impacts, costs and key success factors involved in workplace travel plans.

\section{b) Scale of activities}

The seven case study authorities were asked about the number of companies and employees in their areas in total, and in relation to those that they were working with on workplace travel planning. The results are shown in table 2.

$<$ Insert table 2 about here>

Three of the city authorities (Nottingham, Birmingham and York) had managed to engage organisations representing about $30 \%$ of staff. (Bristol's engagement was lower, with $13 \%$ of staff involved.) In contrast, the larger authorities (Cambridgeshire, Merseyside and Buckinghamshire) had engaged organisations representing 8-12\% of employees (although in Cambridgeshire, the proportion of employees engaged in travel planning rose to $29 \%$ if looking only at the City and South Cambridgeshire, where the local authority had concentrated its efforts on travel plan work). All locations had engaged with only a small fraction of total companies in their local area, and preferred to concentrate their efforts on the larger employers. These data compare with work by Rye (2002) which concluded that, in 2002, workplace travel plans could already be affecting approximately $12 \%$ of the workforce nationally. Many of the other studies of workplace travel plan activities have shown that take-up of workplace travel plans has been increasing substantially over time, and have also clarified that large organisations, and public sector organisations are more likely to be adopting plans. The potential future scale for travel plan activity is discussed in section e).

\section{c) Impacts on car use}

A summary of results from the literature about the impacts of workplace travel plans on car use is given in table 3 .

$<$ Insert table 3 about here> 
The literature suggested that travel plans typically reduce car use by about $15-20 \%$, with higher reductions of perhaps $20-25 \%$ from plans incorporating measures such as parking management and bus subsidy, and lower reductions of perhaps $5-15 \%$ for plans that do not incorporate such measures. Location is not a key determinant of the degree of change in behaviour achieved by travel plans, although organisations in urban locations may be more likely to undertake travel planning, and typically start with lower levels of car use. All plans are individual, and results vary significantly from organisation to organisation.

As well as analysing the literature evidence, each of the case study authorities were asked for any results that they had about the success of individual travel plans in their area, and, also, for any monitoring of the overall effects of their work. All authorities were able to give information about at least one individual plan in their area, and information for a total of 26 organisations was collected.

Averaged across all 26 organisations (representing over 33,000 staff), the weighted average reduction in car driver trips was $17.8 \%{ }^{2}$. (This is remarkably close to the $18 \%$ reduction recorded in Cairns et al. 2002, which was an in-depth study of travel plan effectiveness). For the four case study areas with data from a number of organisations, the average of the recorded results for individual organisations in their areas varied from $-7.5 \%$ to $-27.3 \%$. Three case study areas (Nottingham, Merseyside and Birmingham) also gave estimates of the overall effects of their work. These were in the range of a $10-15 \%$ reduction in car use.

As well as examining 'average' achievements, the distribution of individual travel plan results was also examined. This highlighted that the achievements of employers differ widely. In some cases, a travel plan appeared to have had no effect, as car driving had increased (three examples). Others had achieved a modest reduction in car driving (three organisations reported reductions of less than $5 \%$ ) or more substantial reductions. Specifically, there were 18 organisations which had reduced car driving by more than $10 \%$, including 9 organisations which had reduced car driving by more than a quarter. The distribution of results for the 26 organisations is illustrated in Figure 1.

\section{$<$ Insert figure 1 about here $>$}

This distribution suggests that the overall average result (17.8\%) is reasonably indicative of what a travel plan can achieve, as individual plans are relatively uniformly distributed around that point. Clearly, there were some high performers (achieving reductions in car driver trips of over 35\%), and some disappointments (where travel planning appeared to have made no difference). However, the majority had reduced car driving by between $1 \%$ and $35 \%$ with a typical plan achieving reductions in the range of perhaps $10-30 \%$. One caveat is that the travel plans which had achieved significant reductions in car use were all, almost certainly, relatively well developed plans and would not include the typical experience from organisations which were only just beginning their work, or which had abandoned work at an early stage.

\section{d) Cost-impact ratios}

The seven case study authorities were also asked about expenditure on their workplace travel plan activities, for both current activities and activities in their first

\footnotetext{
${ }^{2}$ As previously mentioned, the change in the proportion of staff commute trips made as a car driver was used as the main measure of workplace travel plan impact.
} 
year of intensive work (together with how long they had been undertaking intensive workplace travel planning promotion). Separately, they were asked to be more specific about staffing and resources devoted to these activities, and a cross-check was made, to ensure that staffing costs had been included in the expenditure discussed. When this was not the case, the figure of $£ 25,000$ per full-time employee was added to give an overall cost of the work. (This process was checked back with the interviewees).

From the information about costs, together with the information about the scale of activities, it was possible to estimate that workplace travel plans were typically costing local authorities between about $£ 2$ and $£ 4$ per year per employee affected, where the high end of the range was associated with longer-term programmes and the implementation of more substantial measures, such as a grant scheme for employers. (Note that this figure does not include the potential costs to individual employers as a result of implementing travel plans. Work by Cairns et al 2002 suggested an average gross cost of $£ 47$ per full time employee for UK employers implementing travel plans, whilst Organisational Coaching/Schreffler estimated costs of $\$ 100-200$ for US and Dutch employers. These estimates do not include any potential cost-savings to the employer from the beneficial results of travel planning, such as improved staff retention, or offsetting funding generated by measures such as introducing car park charges. None of the existing literature gave an alternative estimate of the costs to the authorities of promoting plans to employers).

As well as calculating the costs of programmes, our study also aimed to estimate cost-impact ratios of the work programme undertaken by the case study authorities. The calculations are shown in table 4.

$<$ Insert table 4 about here $>$

To estimate the total expenditure on their programmes, costs were based on the assumption that expenditure had grown linearly from the first year of intensive work to the current year of work. The majority of expenditure by local authorities involved ongoing costs - i.e revenue funding. The small amount of capital expenditure reported was annualised at 3.5\%, in line with Government guidance.

To calculate impacts, two models of the impacts of the authorities' work were developed ${ }^{3}$. The first (Model A) assumed that for all the employees affected by a travel plan, an average reduction in car driver kilometres of $5 \%$ was achieved. The second (Model B) was slightly more complex. In the interview process, the authorities were asked to estimate the proportion of employees affected by travel plans who were in organisations with 'good' travel plans, 'average' travel plans and who were 'just starting work'. Respective reductions in car driver kilometres of $18 \%, 10 \%$ and $0 \%$ were then applied to employees affected by these different categories of plans.

For both models, the impacts of travel work were assumed to increase linearly, from zero, in the first year of intensive work, to current levels, and it was assumed that, even if no more money was spent, there would be some impact in future years, which would decline at a rate of $40 \%$ p.a..

\footnotetext{
${ }^{3}$ In both cases, the reduction in car driver kilometres was assumed to be directly proportional to the reduction in car driver trips, since there was no available evidence on which to base an alternative calculation or which suggested otherwise.
} 
Throughout the cost impact calculations, the assumptions used were designed to be conservative - both the levels of impact and decay rates used were relatively pessimistic given the evidence reviewed.

Given the data about the costs of each programme, and two (conservative) estimations of the impacts of each programme, it was then possible to calculate the costs per kilometre saved. Overall, the calculated cost impact ratios for workplace travel planning ranged from 0.1 pence to 2 pence per kilometre saved.

\section{e) Scaling up activities}

Interviewees were also asked a number of questions about the viability of scaling up their activities over time, including consideration of issues such as saturation (i.e. how far those likely to participate had already been reached). Three interviewees were prepared to give estimates about the possible scale of future work, which implied that the upper limits for activities may lie somewhere between $15 \%$ of the workforce (the estimate from Buckinghamshire) to $40-50 \%$ of the workforce, (the estimated limit given by York and Birmingham). The difference in limits probably partly depends on the type of area, with companies based in urban locations reported to be more willing to participate in traffic reduction initiatives. Interviewees also discussed the potential to increase the effectiveness of travel plans over time, the resources that they would like in order to achieve goals over the next 10 years and a number of other issues for scaling up activities.

\section{Findings for individual measures}

The preceding section has described the type of analysis that was conducted for each of the measures studied. The overall conclusions for each of the measures were as follows:

- Individual workplace travel plans had typically reduced commuter car driving by between $10 \%$ and $30 \%$, though the best ones had achieved significantly more than that. The typical cost to the local authority of promoting workplace travel plans was £2-£4 per affected employee per year. City authorities prioritising workplace travel plans had typically managed to engage with organisations representing about $30 \%$ of the workforce, whilst county authorities had managed to engage with organisations representing about $10 \%$ of the workforce.

- Where school travel plans were implemented across a local authority area, on average, they had cut school run traffic by between $8 \%$ and $15 \%$, with individual, high-performing schools commonly achieving reductions of over $20 \%$, and, sometimes, considerably more. Many local authorities were devoting more resources to school travel work than to workplace travel plans, and some expected to reach nearly all schools in their area in the next 10 years ${ }^{4}$.

- Personalised travel planning initiatives were typically reporting overall average reductions in car driver trips by their target group of $7 \%-15 \%$ in urban areas, and $2-6 \%$ in rural and smaller urban areas. Costs for large scale implementation are likely to be considerably cheaper than those incurred in the pilot projects studied, and could be in the order of less than $£ 20$ per person targeted, (with some suggesting figures of half this magnitude).

\footnotetext{
${ }^{4}$ Since the interview work for our study took place, the Department for Transport and Department for Education and Skills have issued an explicit aim that all schools should have travel plans in place by the end of the decade.
} 
- Public transport information and marketing schemes (as defined earlier) had delivered clearly recorded increases in bus use. Whilst it is never possible to totally separate out the effects of marketing from infrastructure or service improvements, there was evidence suggesting that schemes incorporating targeted information provision, re-branding and/or marketing campaigns had typically achieved twice the patronage increases of those which had not. Citywide budgets for such work of $£ 60,000-£ 300,000$ per year (including public and private sector investment) had helped to deliver city-wide increases in bus use of $1.5 \%-5 \%$ a year, when combined with other improvements.

- Travel awareness campaigns varied in nature, from relatively general campaigns to closely targeted intensive approaches. Both types reported evidence of car use reductions, although intensive approaches had tended to achieve higher levels of individual change. Many were starting to focus on the positive health benefits from alternative transport policies. In many cases, travel awareness campaigns were used to win support for, and perhaps intensify, other specific initiatives, and the potential value of national awareness campaigning was mentioned in relation to many of the other initiatives.

- Car clubs were estimated to lead to an average reduction of 5 privately-owned cars per car club vehicle. They required start-up funding in the order of $£ 50,000$ to $£ 150,000$ per club which should lead to them becoming self-financing. At the time of the study, car clubs were a very new initiative in the UK, and for the first schemes introduced, there had been a tendency to set unrealistic timescales for breaking even, perhaps partly to justify public funding. Initially, car club initiatives had been focused on high density urban residential locations, although there was increasing interest in the viability of low-cost operational models in rural areas.

- Organised car-sharing clearly had effects on overall car use, although these were dependent on other factors, including parking regimes, the balance of users drawn from car driving or from other modes, and the amount of informal car sharing already taking place. Set up and running costs varied significantly and were primarily determined by the extent of associated publicity and marketing that had taken place.

- Teleworking had been growing rapidly, and was typically resulting in a reduction of between 2 and 6 home-work journeys per teleworker per week. Evidence suggested that, although a commonly expressed concern, changes in car use for other purposes, or by other household members, or due to changes in home location, did not substantially offset these reductions in car use. In fact, there were some instances where car use by households of teleworkers had fallen for other journey purposes, as well as for commuting. The costs incurred by employers in promoting telework had often been offset by business savings.

- Teleconferencing had typically reduced overall business travel kilometres by between $10 \%$ and $30 \%$ in organisations that promoted its use. Many commentators have suggested that there is great potential for more widespread use of teleconferencing. However, public sector promotion may be needed to ensure mainstream adoption. Business savings could be substantial, in terms of reduced travel costs and more efficient use of staff time.

- For groceries, at the time of the study, home shopping accounted for less than $5 \%$ of all grocery sales (by value), but was estimated to reach $10 \%-15 \%$ over the 
next decade, leading to potential reductions of $7-11 \%$ in all food shopping vehicle kilometres. Meanwhile, investment in better drop off facilities for all types of home shopping could reduce travel for customers in some circumstances (where their alternative is travelling to a more remote collection point) and could also substantially improve the efficiency of delivery vehicle operations.

The findings reported above describe the main conclusions for each of the individual measures, discussed in their own terms. A core part of the work also involved drawing 'overall' conclusions about the costs and impacts of such measures, including consideration of issues such as 'double counting'. These results are described in the following sections.

\section{Cost impact ratios}

In line with the approach described for workplace travel plans, cost-impact ratios were calculated for all of the measures. Results are given in table 5.

\section{$<$ Insert table 5 about here $>$}

The cost-impact ratios calculated varied from about 0.1 pence to about 10 pence expenditure per vehicle kilometre reduced, with most figures tending to be at the lower end of this range. Those at the upper end of the range typically included some supporting hard measures implementation. In relation to a scenario where a package of soft measures would be implemented intensively - the 'high intensity' scenario outlined in the next section - the approximate average cost (based on existing expenditure) was estimated to be about 1.5 pence per vehicle kilometre saved. These figures should be treated as indicative of orders of magnitude only ${ }^{5}$.

These costs did not include any changes in personal expenditure by the individuals modifying their behaviour, or spending by the private sector (unless a direct grant or contract by the public sector). There was also no discounting to allow for erosion of benefit due to induced traffic. This was in line with the general approach used in the study, which is discussed further in the penultimate section. The figures given also reflected experience to date. Over time, costs may be expected to fall, due to economies of scale which reduce the unit costs of large initiatives, and there may be learning and the development of better methods which increase the effectiveness of soft measures. Longer term, there may be diminishing returns, as the achievable limits to behavioural change are approached.

As well as examining cost impact ratios, the study also looked at the cost-benefit ratio of smarter choice measures. A full cost-benefit analysis was beyond the scope of the study. However, it was possible to make use of other studies which had calculated the congestion relief and other benefits derived from a reduction in vehicle traffic in various conditions. There is a large literature on this subject, (see for example, Potter et al 2003 and Samson et al 2001). At the time of the study, the most authoritative figures used for assessing the value for money in the allocation of public

\footnotetext{
${ }^{5}$ The estimates of costs per vehicle mile reduced are now being used, by others, to calculate the follow-on costs of marginal carbon abatement. However, note that to find the full resource cost of saving carbon by these measures, it is necessary to allow for the net economic costs and benefits of the traffic reductions. In general, the effect of allowing for the wider costs and benefits will tend to be cost-reducing, meaning that the overall net welfare cost of reducing a tonne of carbon by these measures will be reduced, and potentially outweighed by the benefits. This means that the marginal carbon abatement costs for these measures may be more favourable than appears at face value.
} 
funds were those agreed between the Strategic Rail Authority and the Department for Transport for assessing the benefit of shifting 'sensitive' lorry miles from road to rail in particular, the estimated values of congestion costs in a variety of different road conditions (Strategic Rail Authority, 2003) ${ }^{6}$.

These data suggest that each car kilometre removed brings an overall average benefit in reduced congestion of about 15 pence. This figure varies with location, ranging from about 45 pence in city streets, to 3 pence in rural and other urban streets. These figures do not distinguish by time of day: since the benefits of reducing traffic are very sensitive to the level of congestion, the figures would be higher at peak periods. They would also be higher if other external benefits, such as environmental impacts, were included.

Comparing our average calculated costs ( 1.5 pence per car kilometre removed) with the average benefit in congestion relief (15 pence per kilometre removed) therefore indicated that the ratio of benefit: cost was in the order of 10:1 on average, and many times this in congested urban conditions. In short, expenditure on soft measures seems to represent very good value for money in terms of the benefits obtained per pound spent. The issue of induced traffic needs addressing (as discussed below), and, logically, at some stage, diminishing returns should set in, but there was no indication from the evidence reviewed that this was imminent, or that it would erode benefits sufficiently to offset the very positive margin of net benefit, given the time frame and policy range considered.

\section{Overall impacts on traffic}

A final, key question addressed in the study was - what effect could smarter choice measures have on traffic levels in the UK in about 10 years? To consider this question, two scenarios were developed. These were defined as follows:

- Low intensity: a projection of the present rate of expenditure and level of commitment on soft measures, taking account of the existing important initiatives by the most committed local authorities, and commercial initiatives already being undertaken by companies.

- High intensity: a projection based on a substantial expansion of the activity, commitment and resources devoted to smarter choice measures, which would still be consistent with practical and realistic experience, the current judgements of those working at the local level in practical implementation, and feasible levels of expenditure, given known constraints of staffing and funding generally. This scenario presupposed commitment to such measures at both local level and national level, but did allow for a degree of variation according to local circumstances.

Both scenarios were based on the study team's judgement about what could be achieved by a realistic level of commitment to a programme building up over a ten year period. However, the results were not intended to be a 'forecast for 2014', because no allowance was made for other things that would have changed by then (demography, income, economic growth, road user charging, etc.). In addition, no adjustment was made for induced traffic or for synergy, as justified and explained in the following section. However, some adjustments were made to avoid double

\footnotetext{
${ }^{6}$ This data source also includes values for accidents, noise, pollution, climate change, infrastructure costs, a quantitative estimate for other unquantified factors, and adjustments for taxation. However, the non-congestion elements are based on less well established evidence, and were therefore not used in our report.
} 
counting for the effects of initiatives typically aimed at the journey to work (namely, workplace travel plans, car sharing and teleworking).

To assess the impacts of smarter choice measures, a detailed calculation was undertaken. This involved:

1. Calculating 'impact' factors for each of the individual measures

2. Applying these impact factors to base data from the Department for Transport's National Traffic Model, in order to calculate overall traffic impacts for different categories of traffic.

These stages are described in more detail below.

\section{a) Calculating the effects of individual measures}

For each measure, the potential 'impact' of each was estimated, given about ten years of implementation. This was based on estimations about two dimensions 'coverage' and 'effectiveness'. 'Coverage' was defined as being the proportion of the population which might be affected in some way by the measure concerned, whilst 'effectiveness' was defined as being the amount by which car kilometres travelled could be reduced within the affected population. The product of 'coverage' $x$ 'effectiveness' was termed 'impact'. For 6 of the soft factors, there was insufficient information to give different estimates according to area type. The exceptions were workplace travel plans, personalised travel planning, public transport information and marketing, and car clubs: for these, urban and non-urban estimates were calculated separately, and the non-urban estimates were mostly lower because of the generally poorer quality of public transport.

Inevitably, as in any scenario-building exercise, a lot of assumptions were used. These were carefully based on the literature and case study evidence discussed earlier. The main intention was to get an indicative order of magnitude of the potential of smarter choice measures to assess whether, as discussed in the introduction, their potential role could be significant or not. As part of this process, the study team explored the effects of varying the assumptions used, within the range of what seemed credible. Varying the assumptions within this range did not lead to materially different results.

An example of the process used can be given for workplace travel plans, as follows:

- Nature of impact: It was assumed that the impact would be concentrated in the peak period, and mainly on the journey to and from work. (There could also be impacts on business, patient, shopper, student, tourist and other visitor travel, but these were not considered due to lack of data).

- Coverage: It was assumed that there is an upper level to the proportion of the workforce that can be readily engaged in travel plans. At the time of the study, this was assumed to be determined principally by the proportion of employees who worked for public sector organisations and large companies, (although, in practice, the level might be increased by policies which create incentives for smaller organisations to adopt travel plans). Conservatively, it was also assumed that the proportion of the workforce that could be readily engaged would be lower in non-urban areas than in urban areas (since employment may be more dispersed and there may be fewer large employers). These assumptions were consistent with findings from our case studies. Hence, on the basis of these assumptions, interviewee estimates of what could be achieved in the future and what was currently being achieved in the case study areas, it was estimated that perhaps $30-50 \%$ of the workforce might be engaged in urban areas, and $10-20 \%$ 
in non urban areas in 10 years time. It should be noted that these estimates were also conservative because most interviewees' estimates of future coverage were coloured by an assumption of little change in resources, and because experience of working with clusters of SMEs was only just starting to develop.

- Effectiveness: The evidence reviewed suggested that most reasonably welldeveloped travel plans achieve cuts in car use of $0-35 \%$, with a few best practice plans achieving cuts of over $40 \%$ and some delivering no reduction at all. Data from the case study areas suggested that, broadly:

- $10 \%$ of travel plans achieve no change

- $20 \%$ reduce car use by $>0-10 \%$

- $35 \%$ reduce car use by $>10-25 \%$

- $25 \%$ reduce car use by $>25-35 \%$

- $\quad 10 \%$ reduce car use by over $35 \%$.

Consistent with this breakdown, the average reduction in car use from workplace travel plans (including poor-performing, middle-range and good-performing plans) was $18 \%$, and there was no clear distinction in performance between urban and non urban areas. Hence, for both the low intensity and high intensity scenarios, an average effectiveness of $18 \%$ was used. This was not intended to imply that every plan would achieve an $18 \%$ reduction in car use. Some plans would achieve more, and some less. Equally, this was not an assumption that all areas would achieve the same results. Some flagship towns - for example, compact cities with well-developed traffic restraint policies - could do very well, whilst others could do less well. Moreover, it should be noted that estimates of coverage meant that, even in the high intensity scenario, it was assumed that a large number of employers would not be prepared to engage in travel planning at all (representing $50 \%$ of employees in urban areas and $80 \%$ in non urban areas).

Combining this information implied, in ten years time, workplace travel plans could potentially reduce car driver commuter trips by $5 \%$ or $9 \%$ in urban areas, and $2 \%$ or $4 \%$ in non-urban areas.

A similarly detailed procedure was conducted for each of the smarter choice measures considered, based on the evidence from the literature and the case studies. A summary of the impact factors derived for each of the measures is given in table 6 . Low figures correspond to the low intensity scenario whilst high figures correspond to the high intensity scenario.

$<$ Insert table 6 about here $>$

\section{b) Applying these effects to National Transport Model data}

Actual traffic data for 2000 from the Department for Transport's National Transport Model was used as the base for the study calculations, rather than forecast data for some future year. This was partly for the reasons given previously (i.e. the difficulties of allowing for changes in other exogenous factors), and partly to correspond with the approach taken by the other studies that were reviewed. The results could therefore be interpreted as estimating what difference would exist in 2000 , if the UK had vigorously implemented smarter choices measures for the previous decade or so.

The data source made it possible to divide the traffic information (measured in vehicle kilometres) by a number of dimensions. This included divisions into:

- $\quad$ 'Peak weekday' traffic (traffic between 8-9am and 5-6pm Monday - Friday); and 'rest of week' traffic (all traffic outside peak weekday hours);

- 'Urban' and 'non-urban' traffic, where urban traffic was defined as all traffic in 
urban areas with a population of over 10,000;

- Traffic made by different vehicle types (where non-car traffic was treated separately, and assumed to be unaffected by any of the smarter choice measures).

Car traffic was then subdivided into:

- 'Work' travel, 'business' travel and 'other' travel 1999/2001 National Travel Survey data were then used to subdivide the 'other' category into 'escort education', 'shopping', 'personal business' and 'other'.

The impact factors for individual measures could then be applied to the appropriate subcategories of car traffic data. This led to the results shown in table 7.

$<$ Insert table 7 about here>

\section{c) Results}

The results suggested that, under the 'high intensity' scenario, traffic in urban areas could be cut by $14 \%$ overall, and $21 \%$ at peak times. Traffic in non-urban areas could be cut by $8 \%$ overall, and $14 \%$ at peak times. Nationally (across both urban and nonurban areas), traffic could be cut by $11 \%$ overall, and $17 \%$ at peak times.

Under the 'low intensity' scenario, traffic in urban areas could be cut by $3 \%$ overall, and $5 \%$ at peak times. Traffic in non-urban areas could be cut by $2 \%$ overall, and $3 \%$ at peak times. Nationally, traffic could be cut by $2-3 \%$ overall, and $4 \%$ at peak times.

These results are reasonably consistent with those found in the review of previous studies. However, it should be emphasised again that these are projections of what could happen. Achieving such reductions in practice will depend on a number of related factors including the priority and support accorded to such measures, and the extent to which their benefits are locked in by other measures to control induced traffic, in an appropriately supportive context. Some of these issues are now discussed in the next section.

\section{Other issues for consideration}

In undertaking the analysis described above, various general issues arose, which have a central bearing on the results. These are now discussed.

\section{a) Induced traffic}

One concern about any measure which reduces congestion, which applies equally to smarter choice measures, is that such measures have the potential to cause 'induced traffic', which erodes the benefits. (For evidence about induced traffic, see, for example, SACTRA 1994, Goodwin,1996 and Goodwin \& Noland, 2003). Specifically, those individuals choosing to reduce their car use may be simply replaced by other individuals who are attracted by the freer road conditions to increase their car use. Hence, it is critical to 'lock-in' the benefits of such measures with policies to control induced traffic. Without this, soft measures could still succeed in changing which individuals are using cars, therefore potentially resulting in benefits for individuals, but could have much less effect on area wide traffic levels, congestion or environmental impacts. Those consulted in the course of this study broadly supported this logic of 'locking-in' usually expressing it in terms of soft measures being part of an integrated transport strategy, or needing to be supported by 
complementary measures. They frequently emphasised that achieving overall reductions in traffic depended on some or all of such supportive policies as reallocation of road capacity, measures to improve public transport service levels, parking control, traffic calming, pedestrianisation, cycle networks, congestion charging or other traffic restraint, other use of transport prices and fares, speed regulation, or stronger legal enforcement levels.

In the analysis described above, the importance of induced traffic was recognised but not accounted for. Specifically, the behavioural responses expected were not adjusted in either direction, neither allowing for erosion of effects due to induced traffic, nor enhancement of soft factor effects due to the other measures being introduced to prevent induced traffic such as pricing or reallocation of road capacity. This position may be interpreted as an assumption, made for analytical purposes, that 'locking-in' measures would be introduced at just sufficient intensity to maintain the changes brought about by soft measures, but not more. This was primarily to enable the effects of smarter choice measures to be clarified in themselves. (It was not an implied judgement that such a level would be optimal, or, indeed, very likely.)

\section{b) Timescales of behavioural response}

Most studies of the effects of hard measures on behaviour, such as studies of changes in price (involving econometric analysis of time series data) or studies of the expansion or contraction of road capacity (involving analysis of traffic counts), have concluded that effects on behaviour can build up over a period of several years, with typical adjustment periods of 5-10 years, and, in a few cases, up to about 20 years. Theory, logic and intuition, but little evidence, suggests that this build-up process could also apply to the behavioural responses involved in some soft measures. If so, monitoring for only a short period will underestimate the impacts of such measures, after allowing also for the longer term effects of other factors (eg income, car ownership etc) which may be operating in the opposite direction to the behaviour change effect of the measures. Other soft factors, however, may have the effect of shortening the behavioural response period, by making immediate information available, and alternatives worth considering, which would otherwise only filter through to some travellers much more slowly, or not at all. Further, some soft initiatives seem to need reinforcement or refreshment after a period. More understanding of these issues would be useful.

\section{c) Synergy}

There is considerable interest in the potential positive synergies and interactions between different soft measures, and between soft and hard measures. The main mechanisms of synergy are assumed to be: strengthening awareness, intent, or the range of opportunities available; reaching thresholds enabling larger behavioural responses; or reducing offsetting effects which would undermine the impact of the soft factor intervention.

However, there are also concerns about circumstances where interactions may be negative. For example, there is concern that when approaching saturation levels of effect for particular markets, further reductions in car use will be increasingly difficult, or that, if congestion is overcome, this could, itself, reduce the enthusiasm for introducing or responding to soft instruments.

Overall, perhaps, the main significance of arguments about both synergies and negative interactions is that consistent application of soft and hard measures could increase the speed at which maximum realistic behavioural shifts are achieved, and 
inconsistent or partial application could substantially undermine the likelihood of having positive effects. Since our study was completed, the UK Department for Transport has designated three UK towns - Worcester, Peterborough and Darlington - to be 'sustainable travel demonstration towns' and is funding them to implement a range of smarter choice measures, partly to try to identify the synergistic effects that result. Transport for London is also developing a similar initiative, based in the London Borough of Sutton. Cairns (forthcoming) explores the potential synergy between smarter choice measures and road user charging.

\section{d) Policy context}

The literature and the case study interviewees all stressed the importance of the policy context of soft factor interventions, and discussed various barriers to successful implementation, and 'wish-lists' of improvements that would make implementation easier. At local level, officials concerned with developing soft measures often felt that their work was still not recognised as being of central importance in transport strategy, which was affecting resources, political support, career expectations and profile. There was also a perception that the relevant professional skills were not widely available or given sufficient importance. The key, overarching policy initiatives mentioned as being important to achieving the full potential of smarter choice measures were:

- A clear national strategy in favour of traffic reduction, with recognition that smarter choice measures could make a valuable and concrete contribution to this.

- The availability of new revenue funding streams for local authorities, or greater flexibility in the use of capital budgets.

- Specific policies to support particular initiatives, including: more tax breaks for workplace travel plans; a statutory requirement for schools to have travel plans; stronger planning guidance requiring more implementation of smarter choice measures in parallel with new development; greater regulation of public transport and less restrictions on co-operative arrangements between operators; a national lead on engaging with 'hard-to-reach' stakeholders such as leisure providers and trade unions; and greater dissemination of existing national experience.

- Greater implementation of local policies including: reallocation of road capacity, parking restraint, congestion charging and workplace parking levies to encourage workplace travel plans; traffic calming, $20 \mathrm{mph}$ limits, safe crossing facilities and parking restrictions outside schools to complement school travel planning; fasttracking of traffic orders for dedicated parking spaces to facilitate the distribution of car club vehicles; new national parking arrangements for car sharers; and vehicle access restrictions, specific parking rights and investment in local drop-off facilities to encourage home shopping and less polluting logistics systems.

\section{Conclusions}

There is a growing body of practical experience and understanding of the role for smarter choice measures in transport policy. Such interventions provide a number of different ways of encouraging better informed traveller attitudes, and more benign or efficient ways of travelling. The results reported here suggest that, within approximately 10 years, such measures have the potential to reduce national traffic levels by about $11 \%$, with reductions of up to $21 \%$ in peak period urban traffic. Moreover, they represent relatively good value for money, with schemes potentially generating benefit: cost ratios which are in excess of 10:1.

The results of this study perhaps challenge expectations. A key question is - are these results credible, and if not, what is the difficulty? A review presenting a decade 
of transport research by Goodwin et al (2007) offers one answer: this work has highlighted that the amount of inherent variability in individuals' behaviour is already at the sort of levels reported (ca. 20\%), even without policy intervention, but this is not widely known or appreciated, partly because of the dominance of surveys and models which emphasise average or normal behaviour rather than variability in behaviour. Once the present amount of 'churn', and the need for associated supportive measures are factored into expectations, the large numbers generated by the study do not necessarily seem unrealistic. In addition, since the report was published, various agencies have reported results which are broadly in line with the findings of the study, in relation to both individual measures and overall, with particularly promising results emerging from the three Sustainable Travel Demonstration Towns, as reported, for example, in Cairns S (forthcoming).

In a favourable wider policy context, then, smarter choice measures could be sufficiently effective in reducing car use, and offer sufficiently good value for money, that they merit serious consideration for an expanded role in transport strategy. Overall, the effects of soft policies will depend on the scale of implementation chosen as an act of policy by central and local government, associated with, and interacting with, decisions on other policies, including prices, service improvements, traffic control and management and infrastructure changes. However, the central conclusion of the study is that the impact of such measures need not be marginal, and could be very significant in addressing traffic, given the right support. 


\section{References}

Addison L \& Fraser J (2002) Using the planning process to secure travel plans. Report by Addison \& Associates for the Department for Transport, London.

Anable J, Kirkbride A, Sloman L, Newson C, Cairns S and Goodwin P (2004) Smarter choices - changing the way we travel. Case study reports. Department for Transport, London.

Bayliss D (2004) personal correspondence.

Bonsall P (2003) Peer review of Halcrow (2002), Department for Transport, London, unpublished.

Cairns S (forthcoming) Understanding potential synergies between transport policies: Smarter choices and road user charging. Report to Transport for London.

Cairns S, Davis A, Newson C and Swiderska C (2002) Making travel plans work: research report. Report by Transport 2000, ESRC Transport Studies Unit UCL and Adrian Davis Associates for Department for Transport

Cairns S, Sloman L, Newson C, Anable J, Kirkbride A and Goodwin P (2004) Smarter Choices - changing the way we travel. Department for Transport, London.

Dodgson J, Pacey J, Begg M (2000) Motors and Modems Revisited, National Economic Research Associates, London

Dodgson J, Sandbach J, McKinnon A, Shurmer M, van Dijk T, \& Lane B (1997) Motors or Modems, National Economic Research Associates, London

Goodwin P (1996) Empirical evidence on induced traffic: A review and synthesis. Transportation 23, pp35-54

Goodwin P (2003) Peer review of Halcrow (2002), Department for Transport, London, unpublished

Goodwin P, Cairns S, Dargay J, Hanly M, Parkhurst G, Stokes G and Vythoulkas P (2007) 'Practical evidence on the effectiveness of transport policies in reducing car use', in Gärling T and Steg L (eds) Threats to the quality of urban life from car traffic problems, causes and solutions. Elsevier.

Goodwin P and Noland R (2003) Building new roads really does create extra traffic: a response to Prakash et al Applied Economics 35, pp1451-1457

Halcrow Group (2001, 2002) Multi-modal studies: soft factors likely to affect travel demand, update final report, Department for transport, London

Headicar P (2003) Peer review of Halcrow (2002), Department for Transport, London, unpublished

James, A. (2002) Review of Halcrow soft factors report, South West Transport Activists Roundtable, and personal correspondence 2004. 
Ligtermoet D (1998) Zeven jaar vervoermanagement: synthese van ervaringen Report to Adviesdienst Verkeer en Vervoer Netherlands Ministry of Transport, The Hague

Napier University Transport Research Institute, Open University and WS Atkins (2001) Evaluation of Government Departments' Travel Plans Report for DETR, unpublished

Organizational Coaching and Schreffler E (1996) Effective TDM at worksites in the Netherlands and the US Report prepared for the Dutch Ministry of Transport, Public Works and Water Management, Den Haag.

Potter S, Lane B, Parkhurst G, Cairns S \& Enoch M (2003) Evaluation of school and workplace travel plan site specific advice programme Department for Transport, London.

Rye (2002) Travel plans: do they work? Transport Policy 9(4) 287-298

Standing Advisory Committee on Trunk Road Assessment (1994) Trunk roads and the generation of traffic. HMSO, London.

Samson T, CA Nash, PJ Mackie, JD Shires and SM Grant-Muller (2001) Surface Transport Costs and Charges. DETR, London.

Shoup D (1997) Evaluating the effects of cashing out employer-paid parking: eight case studies Transport Policy 4(4) 201-216

Sloman L (2003) Less traffic where people live: how local transport schemes can help cut traffic, Transport for Quality of Life, Machynlleth

Steer Davies Gleave (2001) Take up and effectiveness of travel plans and travel awareness campaigns Report for DETR, London.

Steer Davies Gleave (2003) Weymouth relief road: alternatives to the proposed scheme. SDG, London.

Strategic Rail Authority (2003) Sensitive Lorry Miles: results of analysis, SRA, London.

Touwen, M. (1999) Travel planning in the Randstad: an evaluation based on ReMOVE. Report to Netherlands Ministry of Transport, The Hague

Transit Co-operative Research Program (1994) Cost effectiveness of TDM programs working paper \#2, COMSIS Corporation, Maryland, USA.

Transport for London (2003) Soft options - review of studies. Cited with permission, unpublished committee report

University of Westminster (1998) Levels of activity relating to safer routes to school type projects and green transport plans. Report for DETR

W S Atkins (1999) Assessing the effect of transport white paper policies on national traffic, Final Report and Appendices, DETR, London 
Table 1: Summary of previous studies estimating the 'overall' impacts of smarter choice measures on total traffic levels

\begin{tabular}{|c|c|c|c|c|c|c|c|}
\hline Study & $\begin{array}{l}\text { Dodgson et al } \\
\text { (1997) }\end{array}$ & $\begin{array}{l}\text { WS Atkins } \\
\text { (1999) }\end{array}$ & $\begin{array}{l}\text { Halcrow Group (2001, } \\
\text { 2002) }\end{array}$ & James (2002) & Sloman (2003) & $\begin{array}{l}\text { Steer Davies } \\
\text { Gleave (2003) }\end{array}$ & $\begin{array}{l}\text { Transport for } \\
\text { London (2003) }\end{array}$ \\
\hline $\begin{array}{l}\text { Factors } \\
\text { included }\end{array}$ & $\begin{array}{l}\text { All } \\
\text { telecommunications } \\
\text { (telecommuting, } \\
\text { teleshopping, } \\
\text { teleconferencing, } \\
\text { freight operations) }\end{array}$ & $\begin{array}{l}\text { Workplace and } \\
\text { school travel plans, } \\
\text { improvements to } \\
\text { public transport and } \\
\text { walking facilities, } \\
\text { public transport } \\
\text { fares, parking } \\
\text { restraint, } \\
\text { reallocation of road } \\
\text { capacity, road user } \\
\text { charging, highway } \\
\text { and traffic control } \\
\text { improvements, land } \\
\text { use policies. }\end{array}$ & $\begin{array}{l}\text { Workplace and school travel } \\
\text { plans, visitor travel plans, bus } \\
\text { quality partnerships, } \\
\text { improved public transport } \\
\text { interchange, general public } \\
\text { transport marketing, public } \\
\text { transport fares and ticketing, } \\
\text { individualised marketing, car } \\
\text { clubs, teleworking, video- } \\
\text { conferencing, home } \\
\text { shopping, measures to } \\
\text { increase walking and cycling, } \\
\text { land-use policies, local } \\
\text { sourcing of goods, oil } \\
\text { supplies and new automotive } \\
\text { technology. }\end{array}$ & $\begin{array}{l}\text { Workplace and } \\
\text { school travel plans, } \\
\text { bus quality } \\
\text { partnerships, public } \\
\text { transport } \\
\text { interchange, public } \\
\text { transport marketing } \\
\text { and ticketing, public } \\
\text { transport } \\
\text { information, car } \\
\text { clubs, teleworking, } \\
\text { videoconferencing, } \\
\text { internet shopping, } \\
\text { cycling, promotion } \\
\text { of walking, land use } \\
\text { effects. }\end{array}$ & $\begin{array}{l}\text { Workplace and } \\
\text { school travel } \\
\text { plans, bus quality } \\
\text { partnerships, } \\
\text { local rail } \\
\text { improvements, } \\
\text { individual } \\
\text { marketing, car } \\
\text { clubs, } \\
\text { teleworking, } \\
\text { promotion of } \\
\text { walking and } \\
\text { cycling. }\end{array}$ & $\begin{array}{l}\text { Workplace and } \\
\text { school travel } \\
\text { plans, bus quality } \\
\text { partnerships. } \\
\text { (Visitor travel } \\
\text { plans, rail } \\
\text { improvements, } \\
\text { parking restraint } \\
\text { considered but } \\
\text { impacts not } \\
\text { estimated. } \\
\text { Individual travel } \\
\text { planning } \\
\text { estimated but } \\
\text { largely } \\
\text { discounted to } \\
\text { avoid double } \\
\text { counting.) }\end{array}$ & $\begin{array}{l}\text { Workplace and } \\
\text { school travel plans, } \\
\text { individualised } \\
\text { marketing, car } \\
\text { clubs, car sharing, } \\
\text { teleworking, } \\
\text { videoconferencing, } \\
\text { e-shopping, } \\
\text { promoting cycling, } \\
\text { promoting walking, } \\
\text { travel awareness } \\
\text { campaigns. }\end{array}$ \\
\hline \multicolumn{8}{|c|}{ Maximum combined potential of all included measures } \\
\hline $\begin{array}{l}\text { National } \\
\text { Best Local }\end{array}$ & $\begin{array}{l}-6 \% \text { to }-16 \% \\
\text { not estimated }\end{array}$ & $\begin{array}{l}-15 \% \text { to }-20 \% \\
-25 \% \text { to }-32 \%\end{array}$ & $\begin{array}{l}-5 \% \\
\text { not estimated }\end{array}$ & $\begin{array}{l}-15 \% \text { to }-20 \% \\
\text { not estimated }\end{array}$ & $\begin{array}{l}-4 \% \text { to }-9 \% \\
-12 \% \text { to }-26 \%\end{array}$ & $\begin{array}{l}\text { not estimated } \\
-15 \% \text { to }-19 \%\end{array}$ & $\begin{array}{l}-8 \% \text { to }-17 \% \\
\text { London-wide }\end{array}$ \\
\hline \multicolumn{8}{|c|}{ Maximum potential of work and school travel plans only } \\
\hline $\begin{array}{l}\text { National } \\
\text { Best Local }\end{array}$ & $\begin{array}{l}\text { not estimated } \\
\text { not estimated }\end{array}$ & $\begin{array}{l}-4 \% \\
-9 \%\end{array}$ & $\begin{array}{l}-1 \% \\
\text { not estimated }\end{array}$ & $\begin{array}{l}-3.7 \% \\
\text { not estimated }\end{array}$ & $\begin{array}{l}-1 \% \text { to }-3 \% \\
-3 \% \text { to }-8 \%\end{array}$ & $\begin{array}{l}\text { not estimated } \\
-12 \% \text { to }-15 \%\end{array}$ & $\begin{array}{l}-2 \% \text { to }-4 \% \\
\text { London-wide }\end{array}$ \\
\hline
\end{tabular}

Bold figures as stated explicitly in sources, others inferred. Sloman's figures as in source but recalculated as \% of total traffic. 
Table 2: Summary of the scale of local authority work on travel plans (summer 2003)

\begin{tabular}{|l|c|c|c|c|}
\hline \multicolumn{1}{|c|}{ Location } & $\begin{array}{c}\text { Number of staff in } \\
\text { companies with } \\
\text { workplace travel } \\
\text { plans }\end{array}$ & $\begin{array}{c}\text { Number of } \\
\text { companies that } \\
\text { local authority is } \\
\text { working with }\end{array}$ & $\begin{array}{c}\text { \% staff affected } \\
\text { in local } \\
\text { authority area }\end{array}$ & $\begin{array}{c}\text { \% companies } \\
\text { affected in local } \\
\text { authority area }\end{array}$ \\
\hline Birmingham & 136,000 & $145\left(+20^{*}\right)$ & 29 & $0.5-0.6$ \\
\hline Bristol & 29,960 & $60(+25 \#)$ & 13 & -- \\
\hline Buckinghamshire & 21,700 & 33 & 11 & -- \\
\hline Cambridgeshire & 34,000 & $44\left(+16^{\star}\right)$ & 29 or $12 \sim$ & 0.5 or 0.3 \\
\hline Merseyside & 55,870 & 57 & 8 & -- \\
\hline Nottingham & 52,000 & $35(+265 \#)$ & 28 & 0.5 \\
\hline City of York & 26,187 & 30 & 29 & 0.6 \\
\hline
\end{tabular}

${ }^{*}$ These are support companies - e.g. cycle shops - and non employer steering group members such as the Cambridge cycling campaign.

\# These are members of travel plan networks who are largely inactive, or with whom the council has little involvement

$\sim$ First figure is the \% of employees reached in the two main target districts for Cambridgeshire County Council (Cambridge City and South Cambridgeshire). The second figure is for the percentage of all employees affected throughout the county. 
Table 3: Summary of literature evidence about the impacts of travel plans on car use

\begin{tabular}{|c|c|}
\hline Study & Conclusion^ $^{\wedge}$ \\
\hline $\begin{array}{l}\text { Cairns et al } \\
(2002)\end{array}$ & $\begin{array}{l}\text { A selection of 'good practice' travel plans reduced commuter car } \\
\text { driver trips by an average of at least } 18 \% \text {. Plans which included } \\
\text { parking management measures achieved an average reduction in } \\
\text { car driver trips of }>24 \% \text {, compared with }>10 \% \text { for those that did } \\
\text { not. Organisation location did not determine travel plan } \\
\text { effectiveness }\end{array}$ \\
\hline $\begin{array}{l}\text { Organisational } \\
\text { Coaching and } \\
\text { Shreffler (1996) }\end{array}$ & $\begin{array}{l}\text { Successful travel plans in the US had typically reduced vehicle } \\
\text { trips by } 19 \% \text {. } \\
\text { Successful travel plans in the Netherlands had typically reduced } \\
\text { vehicle mileage by } 20 \% \text {. }\end{array}$ \\
\hline Shoup (1997) & $\begin{array}{l}\text { Eight Californian employers offering cash for parking had reduced } \\
\text { single occupancy driving by an average of } 13 \% \text { and vehicle miles } \\
\text { by } 12 \% \text {. }\end{array}$ \\
\hline TCRP (1994) & $\begin{array}{l}49 \text { US employers with travel plans had achieved an average } \\
\text { vehicle trip reduction of } 15 \% \text {. Averages for different types of plans } \\
\text { were: } \\
9 \% \text { if offering commuting alternatives only (such as van pools) } \\
16 \% \text { if offering financial incentives only (such as bus fare subsidy) } \\
25 \% \text { if offering financial incentives and services }\end{array}$ \\
\hline $\begin{array}{l}\text { Ligtermoet } \\
\text { (1998) }\end{array}$ & $\begin{array}{l}40 \text { Dutch employers (plus an unspecified numbers of others from } \\
\text { review work) provided information about different types of plans. } \\
\text { This suggested average reductions in vehicle kilometres of: } \\
6-10 \% \text { for plans with 'basic' measures } \\
15-23 \% \text { for plans with 'luxury' measures }\end{array}$ \\
\hline Touwen (1999) & $\begin{array}{l}\text { Information from different types of Dutch travel plan suggested } \\
\text { average reductions in single occupancy vehicle kilometres of: } \\
8 \% \text { for plans with 'basic' measures } \\
20 \% \text { for plans with 'luxury' measures }\end{array}$ \\
\hline
\end{tabular}

${ }^{*}$ Data and analysis in several of the cases were judged to lead to an underestimate (of unknown size) of the effects of the travel plan work on car commuting, meaning that only a 'minimum average' could be calculated.

$\wedge$ The literature varies in how the impacts on car travel are reported (i.e. vehicle trips, vehicle kilometres etc.) The results reported here quote the study results in their own terms.

\section{Figure 1: Distribution of individual travel plan results}

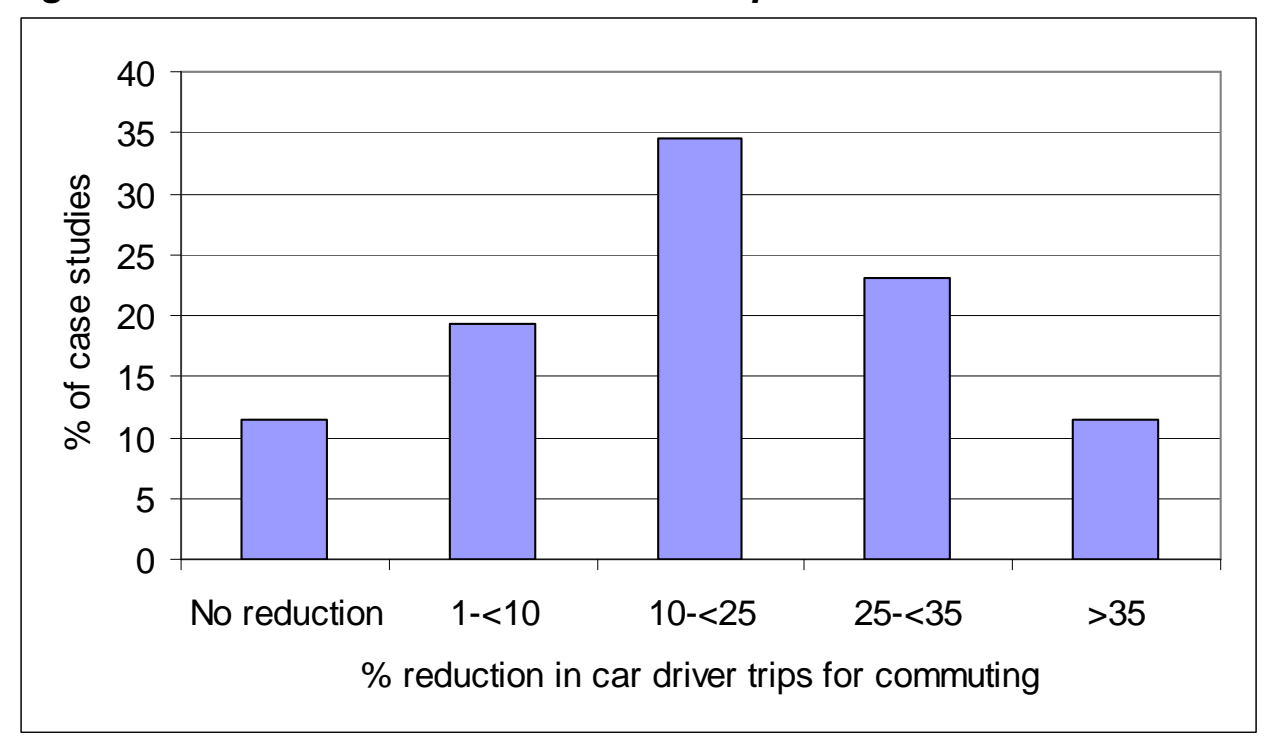


Table 4: Calculation of cost-impact ratios for workplace travel plans

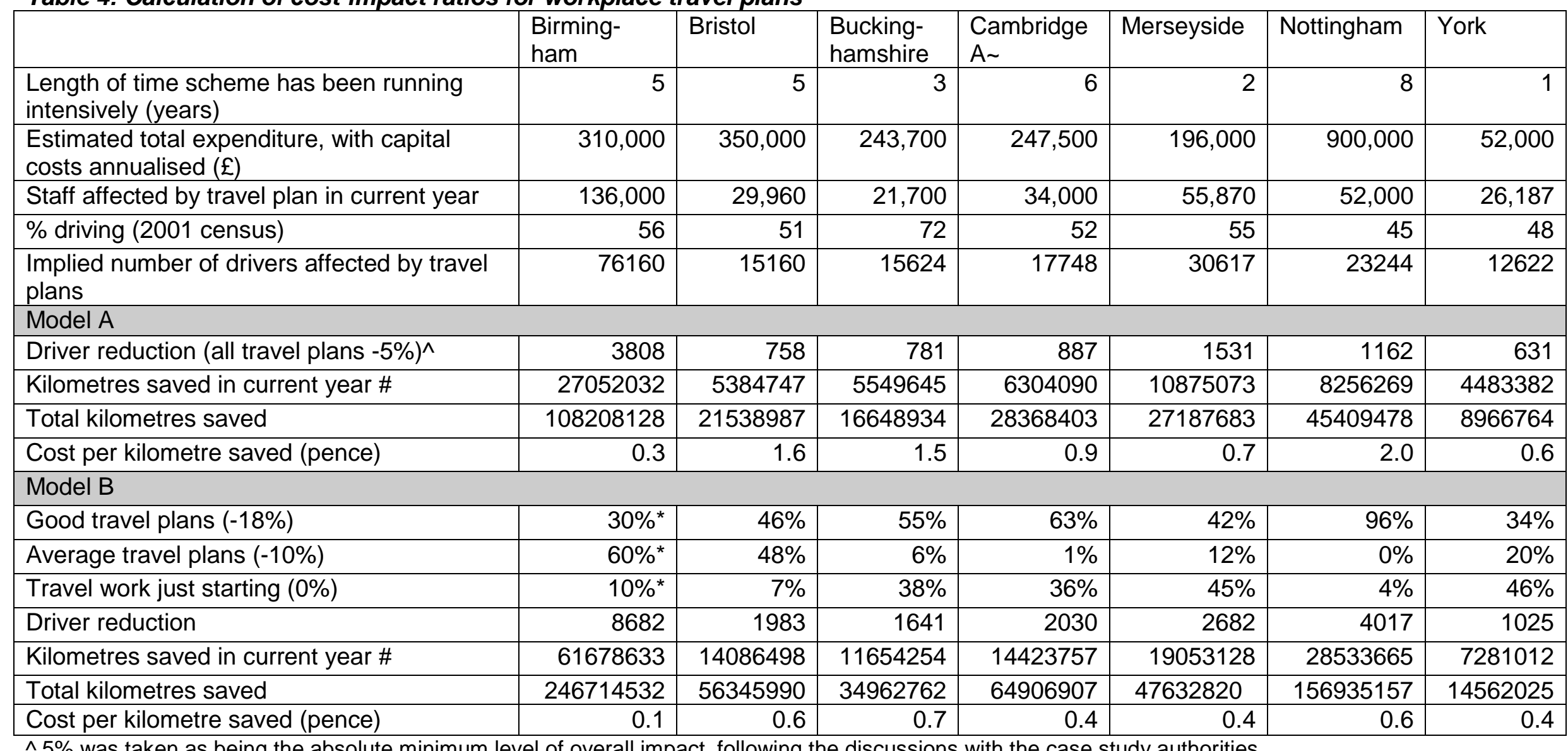

$\wedge 5 \%$ was taken as being the absolute minimum level of overall impact, following the discussions with the case study authorities.

$\sim$ Cambridgeshire A: calculations based on data for the districts of Cambridge City and South Cambridgeshire, where most work has taken place.

\# 'kilometres saved in current year' is derived by assuming that each driver was previously driving for 240 working days and making a daily round trip of

$29.6 \mathrm{kms}$. This is the average distance of a commuter journey by car, according to the 2001 'Travel to work in GB' personal travel factsheet produced by the

DfT and ONS.

* Reflects frequency of contact between employers and Birmingham city council, rather than quality of travel plan. 
Table 5: Indicative public sector costs of smarter choice measures, in pence/vehicle kilometre reduced

\begin{tabular}{|c|c|c|}
\hline Measure & Source & $\begin{array}{c}\text { Indicative cost }^{*} \\
\text { pence/vehicle km reduced }\end{array}$ \\
\hline \multirow{7}{*}{ Workplace travel plans-- } & Birmingham case study & $0.1-0.3$ \\
\hline & Bristol case study & $0.6-1.6$ \\
\hline & Buckinghamshire case study & $0.7-1.5$ \\
\hline & Cambridgeshire case study & $0.4-0.9$ \\
\hline & Merseyside case study & $0.4-0.7$ \\
\hline & Nottingham case study & $0.6-2.0$ \\
\hline & York case study & $0.4-0.6$ \\
\hline \multirow[t]{3}{*}{ School travel plans } & Buckinghamshire case study & $1.4-2.6$ \\
\hline & Merseyside case study & $2.0-3.8$ \\
\hline & York case study & $5.3-9.97$ \\
\hline \multirow{4}{*}{$\begin{array}{l}\text { Personalised travel } \\
\text { planning }\end{array}$} & Gloucester case study (pilot) & 3.3 \\
\hline & Bristol case study (Vivaldi phase 1) & 3.4 \\
\hline & London proposed large-scale & 1.2 \\
\hline & Nottingham proposed large-scale & 0.7 \\
\hline \multirow{2}{*}{$\begin{array}{l}\text { Public transport } \\
\text { information and } \\
\text { marketing + }\end{array}$} & Brighton case study & 4.4 \\
\hline & Nottingham case study & 4.1 \\
\hline Travel awareness & York case study & $0.2-2.7$ \\
\hline \multirow[t]{2}{*}{ Car clubs\# } & Edinburgh case study & 4.8 \\
\hline & Bristol case study & 5.1 \\
\hline \multirow[t]{2}{*}{ Car-sharing } & Buckinghamshire case study & 3.3 \\
\hline & Milton Keynes case study & 0.7 \\
\hline Teleworking & \multirow{3}{*}{\multicolumn{2}{|c|}{$\begin{array}{l}\text { In all three cases, private sector investment is needed, but cost } \\
\text { savings should outweigh investment costs. However, public sector } \\
\text { intervention may be needed to stimulate developments and } \\
\text { changes in business practice }{ }^{\wedge} \text {. }\end{array}$}} \\
\hline Tele-conferencing & & \\
\hline Home shopping & & \\
\hline
\end{tabular}

* Use of decimal places (eg in $0.2 p$ ) should not be read as greater precision than $1 p, 5 p$ etc.. Capital costs have been annualised at 3.5\%. No allowance has been made for induced traffic.

-- Excludes spending by the private sector. It is probable that private employers will only invest in travel plans if they see offsetting benefits, such as reduced parking requirements, improved staff recruitment and retention, obtaining commercially valuable planning permissions, etc. In some cases, employers have managed entirely to fund travel plans from car parking charges.

$\neg$ York's school travel cost figures were high because they included a substantial amount of safer routes work, as well as the 'softer' elements of school travel plans. Such engineering work is often essential to school travel plans, but, in many authorities, it is partly borne by the road safety budget, not simply by the school travel plans budget.

${ }^{+}$Costs include public investment only. Investment by commercial operators is assumed to be motivated, and therefore at least offset, by revenue generated by additional passengers. (Net costs would be even less where revenue from additional passengers exceeds investment by the operator).

\# It is likely that car clubs will become cheaper, and eventually 'free', at the point when they become selffinancing.

$\wedge^{\wedge}$ For telework, we estimated that the British Telecom (BT) initiative had reduced travel at a cost of 1.2 pence per km, in terms of the costs to BT of facilitating teleworking. However, this calculation did not include offsetting savings. For example, BT estimated that telework has contributed to their office space savings worth $£ 180$ million per year.

For teleconferencing, one company reported that videoconferencing equipment paid for itself within the first week of each month in terms of reduced travel costs and staff time savings, and numerous other companies also reported financial savings from adopting teleconferencing. However, public sector promotion, advice and grants may be needed to encourage greater adoption of teleconferencing as mainstream practice, which are currently impossible to cost. 
For home shopping, provision of services is largely occurring for commercial reasons anyway. However, public sector promotion of home shopping for groceries could help to increase take-up, and funding for local drop-off facilities could help to make freight operations more efficient.

Table 6: Summary of impacts of different types of soft measure

\begin{tabular}{|c|c|c|c|c|c|}
\hline \multirow{3}{*}{ Journey purpose } & \multirow{3}{*}{ Soft measure } & \multicolumn{4}{|c|}{ Impact $^{\star} \sim$} \\
\hline & & \multicolumn{2}{|c|}{ Non-urban } & \multicolumn{2}{|c|}{ Urban } \\
\hline & & Low & High & Low & High \\
\hline \multirow[t]{3}{*}{ Journey to work } & Workplace travel plans & $2 \%$ & $4 \%$ & $5 \%$ & $9 \%$ \\
\hline & Car sharing & $0 . .6 \%$ & $11 \%$ & $0.6 \%$ & $11 \%$ \\
\hline & Teleworking & $3 \%$ & $12 \%$ & $3 \%$ & $12 \%$ \\
\hline \multicolumn{2}{|c|}{$\begin{array}{l}\text { Combined impact of workplace travel plans, car } \\
\text { sharing and teleworking, allowing for double counting }\end{array}$} & $5 \%$ & $24 \%$ & $8 \%$ & $26 \%$ \\
\hline Journey to school & School travel plans & $4 \%$ & $20 \%$ & $4 \%$ & $20 \%$ \\
\hline Business journeys & Tele-conferencing & $2.5 \%$ & $18 \%$ & $2.5 \%$ & $18 \%$ \\
\hline Shopping trips & $\begin{array}{l}\text { Home shopping for } \\
\text { groceries }\end{array}$ & $1 \%$ & $4 \%$ & $1 \%$ & $4 \%$ \\
\hline Personal business trips & Local collection points & $1.5 \%$ & $1.5 \%$ & $1.5 \%$ & $1.5 \%$ \\
\hline \multirow[t]{4}{*}{$\begin{array}{l}\text { Multiple journey } \\
\text { purposes }\end{array}$} & $\begin{array}{l}\text { Personalised travel } \\
\text { planning }\end{array}$ & $<1 \%$ & $<1 \%$ & $1 \%$ & $3 \%$ \\
\hline & $\begin{array}{l}\text { Public transport information } \\
\text { and marketing }\end{array}$ & $0.1 \%$ & $0.3 \%$ & $0.3 \%$ & $1.1 \%$ \\
\hline & $\begin{array}{l}\text { Travel awareness } \\
\text { campaigns }\end{array}$ & $0.1 \%$ & $1 \%$ & $0.1 \%$ & $1 \%$ \\
\hline & Car clubs & & & $0.03 \%$ & $\begin{array}{c}0.06 \% \text { (up } \\
\text { to 3\% } \\
\text { longer } \\
\text { term) }\end{array}$ \\
\hline
\end{tabular}

$\sim$ Note that for soft factors which affect multiple journey purposes, the impact is expressed relative to all car travel. For soft factors which affect only one journey purpose, it is expressed relative to car travel for that purpose.

* Impact is expressed as a percentage reduction in car kilometres for the relevant journey purposes for car clubs, car sharing, home shopping for groceries and local collection points. For all other measures, the impact is expressed as a percentage reduction in car trips for the relevant journey purposes. These figures were also applied to car kilometres, as there was no information from either the literature or the case studies that would enable the reliable calculation of different figures for kilometres.

Table 7: Impacts of soft factors on future traffic levels

\begin{tabular}{|l|c|c|}
\hline Impact on... & $\begin{array}{c}\text { Low intensity } \\
\text { scenario }\end{array}$ & $\begin{array}{c}\text { High intensity } \\
\text { scenario }\end{array}$ \\
\hline National traffic & $2 \%$ & $11 \%$ \\
\hline Peak-time national traffic & $4 \%$ & $17 \%$ \\
\hline Off-peak national traffic & $2 \%$ & $10 \%$ \\
\hline Urban traffic & $3 \%$ & $14 \%$ \\
\hline Peak-time urban traffic & $5 \%$ & $21 \%$ \\
\hline Off-peak urban traffic & $3 \%$ & $13 \%$ \\
\hline Non-urban traffic & $2 \%$ & $8 \%$ \\
\hline Peak-time non-urban traffic & $3 \%$ & $14 \%$ \\
\hline Off-peak non-urban traffic & $1 \%$ & $7 \%$ \\
\hline
\end{tabular}

